\title{
Patients with pacemakers or defibrillators do not need to worry about e-Cars: An observational study
}

\author{
Carsten Lennerz ${ }^{\mathrm{a}, \mathrm{e}, *}$, Lorenz Horlbeck ${ }^{\mathrm{b}}$, Severin Weigand ${ }^{\mathrm{a}, \mathrm{e}}$, Christian Grebmer $^{\mathrm{a}}$, \\ Patrick Blazek $^{\mathrm{a}}$, Amir Brkic ${ }^{\mathrm{a}}$, Verena Semmler ${ }^{\mathrm{a}}$, Bernhard Haller ${ }^{\mathrm{c}}$, Tilko Reents ${ }^{\mathrm{a}}$, \\ Gabriele Hessling ${ }^{\mathrm{a}}$, Isabel Deisenhofer ${ }^{\mathrm{a}}$, Markus Lienkamp ${ }^{\mathrm{b}}$, Christof Kolb ${ }^{\mathrm{a}}$ and \\ Matthew O'Connor ${ }^{\mathrm{d}}$ \\ ${ }^{a}$ Deutsches Herzzentrum München, Klinik für Herz- und Kreislauferkrankungen, Abteilung für \\ Elektrophysiologie, Faculty of Medicine, Technische Universität München, Munich, Germany \\ ${ }^{\mathrm{b}}$ Institute of Automotive Technology, Department of Mechanical Engineering, Technische Universität \\ München, Munich, Germany \\ ${ }^{\mathrm{c}}$ Klinikum Rechts Der Isar, Institut für Medizinische Statistik und Epidemiologie, Technische \\ Universität München, Munich, Germany \\ ${ }^{\mathrm{d}}$ Wellington Hospital, Department of Cardiology, Wellington, New Zealand \\ ${ }^{\mathrm{e}}$ German Centre for Cardiovascular Research, Partner Site Munich Heart Alliance, Munich, Germany
}

Received 27 July 2019

Accepted 25 September 2019

\begin{abstract}
.
BACKGROUND: Electric cars are increasingly used for public and private transportation and represent possible sources of electromagnetic interference (EMI). Potential implications for patients with cardiac implantable electronic devices (CIED) range from unnecessary driving restrictions to life-threatening device malfunction. This prospective, cross-sectional study was designed to assess the EMI risk of electric cars on CIED function.

METHODS: One hundred and eight consecutive patients with CIEDs presenting for routine follow-up between May 2014 and January 2015 were enrolled in the study. The participants were exposed to electromagnetic fields generated by the four most common electric cars (Nissan Leaf, Tesla Model S, BMW i3, VW eUp) while roller-bench test-driving at Institute of Automotive Technology, Department of Mechanical Engineering, Technical University, Munich. The primary endpoint was any abnormalities in CIED function (e.g. oversensing with pacing-inhibition, inappropriate therapy or mode-switching) while driving or charging electric cars as assessed by electrocardiographic recordings and device interrogation.

RESULTS: No change in device function or programming was seen in this cohort which is representative of contemporary CIED devices. The largest electromagnetic field detected was along the charging cable during high current charging $(116.5 \mu \mathrm{T})$. The field strength in the cabin was lower $(2.1-3.6 \mu \mathrm{T})$.

CONCLUSIONS: Electric cars produce electromagnetic fields; however, they did not affect CIED function or programming in our cohort. Driving and charging of electric cars is likely safe for patients with CIEDs.
\end{abstract}

Keywords: Electric cars, electromagnetic interference (EMI), cardiac implantable electronic devices (CIED), pacemaker, defibrillator

\footnotetext{
${ }^{*}$ Corresponding author: Carsten Lennerz, Deutsches Herzzentrum München, Klinik für Herz- und Kreislauferkrankungen, Abteilung für Elektrophysiologie, Faculty of Medicine, Technische Universität München, Munich, Germany. Tel.: +49 891218 2947; Fax: +49 891218 4593; E-mail: lennerz@dhm.mhn.de.
} 


\section{Introduction}

Cardiac implantable electronic devices (CIEDs) such as permanent pacemakers (PMs), implantable cardioverter-defibrillators (ICDs) and cardiac resynchronization therapy (CRT) devices are standard of care for treatment of certain bradycardias, tachycardias, and heart failure [1-4]. The prevalence of CIEDs is increasing [5-7].

Exposure to electromagnetic fields generated by everyday electrical equipment is ubiquitous; for example, communication and office equipment (e.g. cellular phones), household appliances (e.g. washing machines, dishwashers), power tools and industrial machines (e.g. welding equipment), and security devices (e.g. metal detectors) [8,9]. In vitro studies demonstrate the potential for electromagnetic fields generated by electronic devices to be sensed by CIEDs and erroneously attributed to intrinsic intracardiac signals $[10,11]$. This electromagnetic interference (EMI) can affect CIED function; resulting in pacing inhibition, delivery of inappropriate anti-tachycardia therapy (due to oversensing), or changes to programmed CIED parameters [12,13]. CIED manufacturers are aware of potential risks and, in addition to providing patient education [14,15], they mitigate EMI risk through improved noise-detection algorithms, shielding and filters for problematic frequencies. Adverse events are rare, but still occur [16-20].

Electric cars are a potential, emerging EMI source. The popularity of electric cars has grown and growth is predicted to continue aided by superior fuel efficiency and incentives to operate low-emission vehicles [21-23]. Therefore, increasing numbers of patients will be exposed to EMI via private vehicles and public transport. However, there is no data regarding the safety of electric cars for patients with CIEDs, nor is there evidence whether restrictions on patients with CIEDs are required. Device manufacturers recommend patients with CIEDs maintain a distance of at least $30 \mathrm{~cm}$ from engine ignition systems and electric boat motors [14,15]. The engines of modern electric cars have outputs significantly larger than average ignition systems (60-310 kW vs 1-2 kW, respectively) [24-26]; however, there are no specific recommendations for electric car use.

The potential for EMI increases with the strength of electromagnetic field, which is proportional to the power of the electric motor. To assess this potential risk, we conducted in vivo evaluation of CIED function during exposure to driving and charging the four most popular electric cars in Europe [27]. The primary results of this study have been previously published as a brief research report in Annals of Internal Medicine, but the methodological details and specific device and leads characteristics are reported here [28].

\section{Methods}

\subsection{Statistics and sample size calculation}

At the time of the study, there was no data on potential EMI between CIEDs and electric cars. Therefore, we based our sample size on the number required to detect common events; i.e., 1-10\% [29]. Hence, we calculated 100 patients were required to observe at least one EMI event with a probability of $99.4 \%$ if the EMI event rate was 5\%. With an estimated drop-out rate of $10 \%$, the target sample size was 110 patients. Data are presented as numbers and percentage and mean \pm standard deviation (SD).

\subsection{Participants}

Consecutive patients presenting for routine follow-up of PM, ICD or CRT function at our institution, 
Table 1

Patient and device characteristics

\begin{tabular}{lc}
\hline Patient & \\
Total number & 108 \\
Men & $90(83 \%)$ \\
Age (years) & $58 \pm 15$ \\
Indication & \\
Indication for anti-bradycardia therapy (PM) & $34(31 \%)$ \\
$\quad$ Sinus-node dysfunction & $16(15 \%)$ \\
Atrioventricular block & $17(16 \%)$ \\
Carotid sinus syndrome & $1(1 \%)$ \\
Indication for anti-tachycardia therapy (ICD) & $74(69 \%)$ \\
$\quad$ Primary prevention of SCD & $40(37 \%)$ \\
Secondary prevention of SCD & $34(31 \%)$ \\
Pacing mode & \\
VVI or VVIR & $37(34 \%)$ \\
VVIRV & $2(2 \%)$ \\
DDD or DDDR & $48(44 \%)$ \\
DDDOV or DDDRV & $21(19 \%)$ \\
\hline
\end{tabular}

Values given as number with percentage in parentheses except age. ${ }^{\dagger}$ including patients with combined sinus node and atrioventricular node dysfunction. $\mathrm{SCD}=$ sudden cardiac death.

between May 2014 and January 2015 were assessed for eligibility. Of 150, 40 declined to participate and two withdrew consent. Hence, we studied 108 patients. This cohort was predominantly male (83\%) with a mean age of $58 \pm 15$ years. Two thirds were ICD-recipients and one third had pacing indications only (Table 1). No patients met our exclusion criteria; suspected lead malfunction, battery life less than three months or intrinsic heart rates $>120 / \mathrm{min}$. Informed consent was obtained.

\subsection{Electric cars}

The four electric cars with the largest market-share in Europe at the time of the study were evaluated: Nissan LEAF, Tesla Model S P85, BMW i3 and VW eUp [27]. All are full electric cars, but with different motor power, torque, battery-size and charging properties (Table 2). Hybrid electric vehicles, combining electric propulsion with conventional powertrain were excluded, because pure electric mode of operation (with associated maximal electromagnetic field) could not be ensured during testing.

\subsection{Roller dynamometer test-bench}

Driving simulation took place on a roller dynamometer test-bench at the Institute of Automotive Technology, Department of Mechanical Engineering, Technical University of Munich, Germany. The roller test-bench enabled programmed simulation of dynamic driving resistances encountered in real life. Additionally, the roller-bench facilitates safe, standardised and reproducible test cycles with maximal acceleration and deceleration protocols; essential to obtain maximal engine torque and subsequent maximal electromagnetic field generation [32].

\subsection{Measurement of electromagnetic fields}

Magnetic field strength was measured as a surrogate for electromagnetic field strength. There is a direct relationship between magnetic and electromagnetic field strength which permits the use of this 
Table 2

Properties of the tested electric cars on the test-bench $[24,25,29,30]$

\begin{tabular}{lllll} 
Electric Car & Nissan LEAF & Tesla Model S P85 & BMW i3 & VW eUp \\
\hline $\begin{array}{l}\text { Max. motor power } \\
\text { (kW) }\end{array}$ & 80 & 310 & 125 & 60 \\
\hline $\begin{array}{l}\text { Max. motor torque } \\
\text { (Nm) }\end{array}$ & 280 & 600 & 250 & 18.7 \\
\hline $\begin{array}{l}\text { Battery size (kWh) } \\
\text { Charge current (A) }\end{array}$ & 16 & 85 & 18.8 & 10 \\
\hline \begin{tabular}{l} 
Charge power (kW) \\
\hline
\end{tabular} & 11 & $20 / 32$ & 20 & 2.3 \\
\hline
\end{tabular}

Table 3

Test protocols

\begin{tabular}{cl}
\hline Test drive number & \multicolumn{1}{c}{ Protocol } \\
\hline 1 & Maximal acceleration to $30 \mathrm{~km} / \mathrm{h}$ followed by braking to a full stop \\
2 & Maximal acceleration to $50 \mathrm{~km} / \mathrm{h}$ followed by braking to a full stop \\
3 & Maximal acceleration to $80 \mathrm{~km} / \mathrm{h}$ followed by braking to a full stop \\
4 & Maximal acceleration to $120 \mathrm{~km} / \mathrm{h}$ followed by braking to a full stop \\
\hline
\end{tabular}

surrogate measurement. The magnetic field meter used was a calibrated ELT 400 (Narda-STS, Pfullingen, Germany) and a B-field probe (three orthogonal coils; total sensing area $=100 \mathrm{~cm}^{2}$; frequency detection range $1 \mathrm{~Hz}$ to $400 \mathrm{kHz}$ ). We used a probe with a large sensing area in case the fields measured were heterogeneous. The magnetic field tester is compliant with CE standard IEC/EN 62233 and Generic Standard IEC 62311, and limit value tracing conforms with ICNIRP 1998, 2010 and EMF Directive 2013/35/EU. The magnetic field was measured in and around the cars during the roller-bench test. The locations measured were in front and behind the cars, beside both front and back doors, in the front seat, and along the charging cable during re-charging. Further measurements of magnetic field strength were taken inside the cabins of all four cars whilst driving on public roads.

\subsection{Test protocol}

Patients underwent routine device interrogation following our standardized device follow-up protocol including evaluation of battery status, pacing and sensing thresholds, lead impedances and review of CIED event monitors. In all patients, ventricular pacing was ensured by increasing the basic pacing rate or by adjusting the atrio-ventricular delay in dual chamber devices. Pre-programmed sensitivity levels were unchanged. In ICDs, tachyarrhythmia detection algorithms were set to the minimum number of intervals to enhance the probability of inappropriate arrhythmia detection. ICD shocks were disabled 
Table 4

CIEDs tested for EMI from electric cars

\begin{tabular}{|c|c|c|c|}
\hline Manufacturer & Device & Number of device tested & Type of device \\
\hline \multicolumn{4}{|l|}{ Biotronik } \\
\hline & Cylos & 1 & PM \\
\hline & Ecuro & 1 & PM \\
\hline & Effecta & 1 & PM \\
\hline & Iforia & 3 & ICD \\
\hline & Lumax & 8 & ICD \\
\hline & Philos & 1 & PM \\
\hline & Talos & 1 & PM \\
\hline \multicolumn{4}{|l|}{ Boston scientific } \\
\hline & Advantio & 1 & PM \\
\hline & Altrua & 1 & PM \\
\hline & Cognis & 3 & ICD \\
\hline & Dynagen & 1 & ICD \\
\hline & Energen & 1 & ICD \\
\hline & Incepta & 1 & ICD \\
\hline & Ingenio & 2 & PM \\
\hline & Inogen & 1 & ICD \\
\hline & Punctua & 1 & ICD \\
\hline \multicolumn{4}{|l|}{ Guidant } \\
\hline & Altrua & 1 & PM \\
\hline & Vitality & 2 & ICD \\
\hline \multicolumn{4}{|l|}{ Medtronic } \\
\hline & Adapta & 1 & PM \\
\hline & Cardia & 1 & ICD \\
\hline & Entrust & 2 & ICD \\
\hline & Maximo & 2 & ICD \\
\hline & Protecta & 5 & ICD \\
\hline & Secura & 4 & ICD \\
\hline & Sensia & 5 & PM \\
\hline & Viva & 2 & ICD \\
\hline \multicolumn{4}{|l|}{ Sorin } \\
\hline & Ovatio & 2 & ICD \\
\hline & Paradym & 11 & ICD \\
\hline & Reply & 3 & PM \\
\hline \multicolumn{4}{|l|}{ St. Jude Medical } \\
\hline & Current & 3 & ICD \\
\hline & Ellipse & 3 & ICD \\
\hline & Fortify & 11 & ICD \\
\hline & Identity & 1 & PM \\
\hline & Promote & 2 & ICD \\
\hline & Sustain & 2 & PM \\
\hline & Unify & 5 & ICD \\
\hline & Verity & 2 & $\mathrm{PM}$ \\
\hline & Victory & 2 & PM \\
\hline & Zephyr & 2 & PM \\
\hline \multicolumn{4}{|l|}{ Vitatron } \\
\hline & $\begin{array}{l}C 20 \\
\text { C } 60\end{array}$ & $\begin{array}{l}1 \\
3\end{array}$ & $\begin{array}{l}\text { PM } \\
\text { PM }\end{array}$ \\
\hline
\end{tabular}

$\mathrm{ICD}=$ implantable cardioverter defibrillator, $\mathrm{PM}=$ pacemaker.

during the study where applicable. This optimized CIED programming for identification of EMI have been established in other EMI-studies [33-35].

Patients sat in the front seat of the cars while on the test-bench and the electromagnetic field strength 
Table 5

Leads tested for EMI from electric cars

\begin{tabular}{|c|c|c|}
\hline Manufacturer & Lead & $n$ \\
\hline \multicolumn{3}{|l|}{ Biotronik } \\
\hline & Corox & 4 \\
\hline & Linox & 9 \\
\hline & Safio & 3 \\
\hline & Selox & 1 \\
\hline & Sentus & 2 \\
\hline & Setrox & 7 \\
\hline & Siello & 20 \\
\hline & Solia & 4 \\
\hline & Synox & 1 \\
\hline & Y-53 & 1 \\
\hline \multicolumn{3}{|l|}{ Boston Scientific } \\
\hline & Easytrak 3 & 1 \\
\hline & Endotak Reliance & 4 \\
\hline & Flextend & 3 \\
\hline & Reliance 4-Front & 1 \\
\hline \multicolumn{3}{|l|}{ Guidant } \\
\hline & Easytrak 2 & 2 \\
\hline & Endotak Endurance & 1 \\
\hline & Endotak Reliance & 6 \\
\hline \multicolumn{3}{|l|}{ LivaNova/Sorin } \\
\hline & Beflex & 2 \\
\hline & Tilda & 1 \\
\hline & Vigila & 2 \\
\hline & Volta & 1 \\
\hline \multicolumn{3}{|l|}{ Medtronic } \\
\hline & 4057 & 3 \\
\hline & 4598 & 1 \\
\hline & Attain & 2 \\
\hline & Attain StarFix & 1 \\
\hline & CapSureEpi & 2 \\
\hline & CapSureFix Novus & 12 \\
\hline & CapSure Sense & 2 \\
\hline & CapSure SP & 3 \\
\hline & CapSure SP Novus & 4 \\
\hline & Sprint & 1 \\
\hline & Sprint Fidelis & 4 \\
\hline & Sprint Quattro & 5 \\
\hline & Sprint Quattro Secure & 5 \\
\hline \multicolumn{3}{|l|}{ St. Jude Medical } \\
\hline & Durata & 26 \\
\hline & IsoFlex & 1 \\
\hline & OptiSense & 3 \\
\hline & QuickFlex & 8 \\
\hline & QuickSite & 1 \\
\hline & Riata & 6 \\
\hline & Tendril & 34 \\
\hline \multicolumn{3}{|l|}{ Vitatron } \\
\hline Unknown & IMD49B Excellence+ & 2 \\
\hline
\end{tabular}


Electric Car

BMW i3

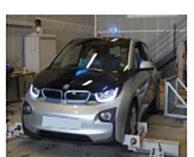

Nissan Leaf

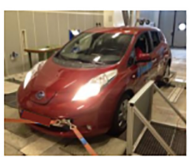

Tesla Model 855

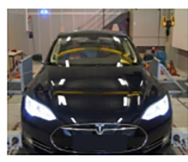

vw e-up!

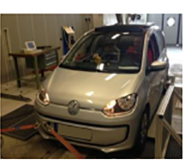

Magnetic Field Measurements*

Around vehicle During acceleration $(0-120 \mathrm{~km} / \mathrm{h})$
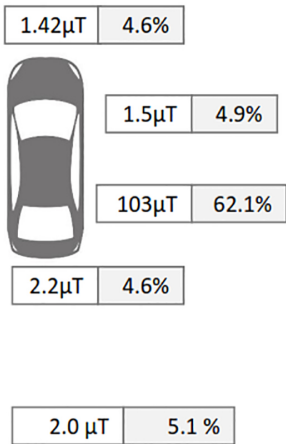

At the front seat Close to the Device (peak values)

Along the cable During charging (peak values) \begin{tabular}{|l|l}
\hline $54.5 \mu \mathrm{T}$ & $33.6 \%$ \\
\hline
\end{tabular}

During a 20A charge
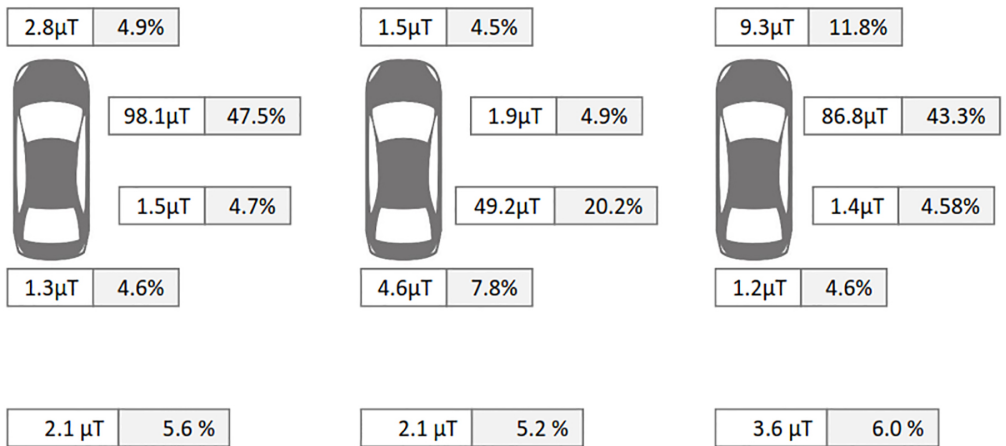

$$
\begin{array}{|c|r|}
\hline 30.1 \mu \mathrm{T} & 28.9 \% \\
\hline
\end{array}
$$

During a 16A charge

\begin{tabular}{|c|c|}
\hline $2.1 \mu \mathrm{T}$ & $5.2 \%$ \\
\hline $78.0 \mu \mathrm{T}$ & $50.0 \%$ \\
\hline \multicolumn{2}{|c|}{ During a $20 \mathrm{~A}$ charge } \\
\hline $116.5 \mu \mathrm{T}$ & $89.6 \%$ \\
\hline
\end{tabular}

Fig. 1. Magnetic field strength during testing. ${ }^{*}$ Values displayed as maximal field strength and as a percentage (normalized by frequency) of the maximum recommended exposure by ICNIRP [36]. Adapted from Ann Intern Med with permission [28].

within $5 \mathrm{~cm}$ of the CIED was recorded. Under continuous 6-lead ECG recording patients were instructed to perform pre-defined maximal accelerations and decelerations (Table 3). Patients then charged the car; this included plugging in, holding and unplugging the charger cable under continuous ECG-monitoring. Each patient performed this protocol with a single car.

All ECGs were analyzed for abnormal CIED function; e.g. inhibition of pacing, loss of capture, tracking to the upper rate limit or inappropriate mode switch. Device event monitors were interrogated for ventricular over-sensing resulting in inappropriate tachyarrhythmia detection. After each test, the device settings were compared with the initial settings to identify spontaneous reprogramming and the CIED subsequently reprogrammed to the settings specific for that patient.

All ECG recordings were independently analyzed by two cardiologists blinded to patient and car.

The study was approved by the ethics committee of Technical University of Munich, Munich, Germany and registered with clinicaltrials.gov (NCT02252575).

\section{Results}

\subsection{Device types}

One hundred and eight CIEDs comprising 42 different CIED families from 7 manufacturers were tested (Table 4). Of the 108 CIEDs 46 (42.6\%) were dual chamber or CRT-ICDs, 28 (26\%) were single chamber ICDs, 31 (28.7\%) were dual chamber PMs, and 3 (2.7\%) were single chamber PMs. One 


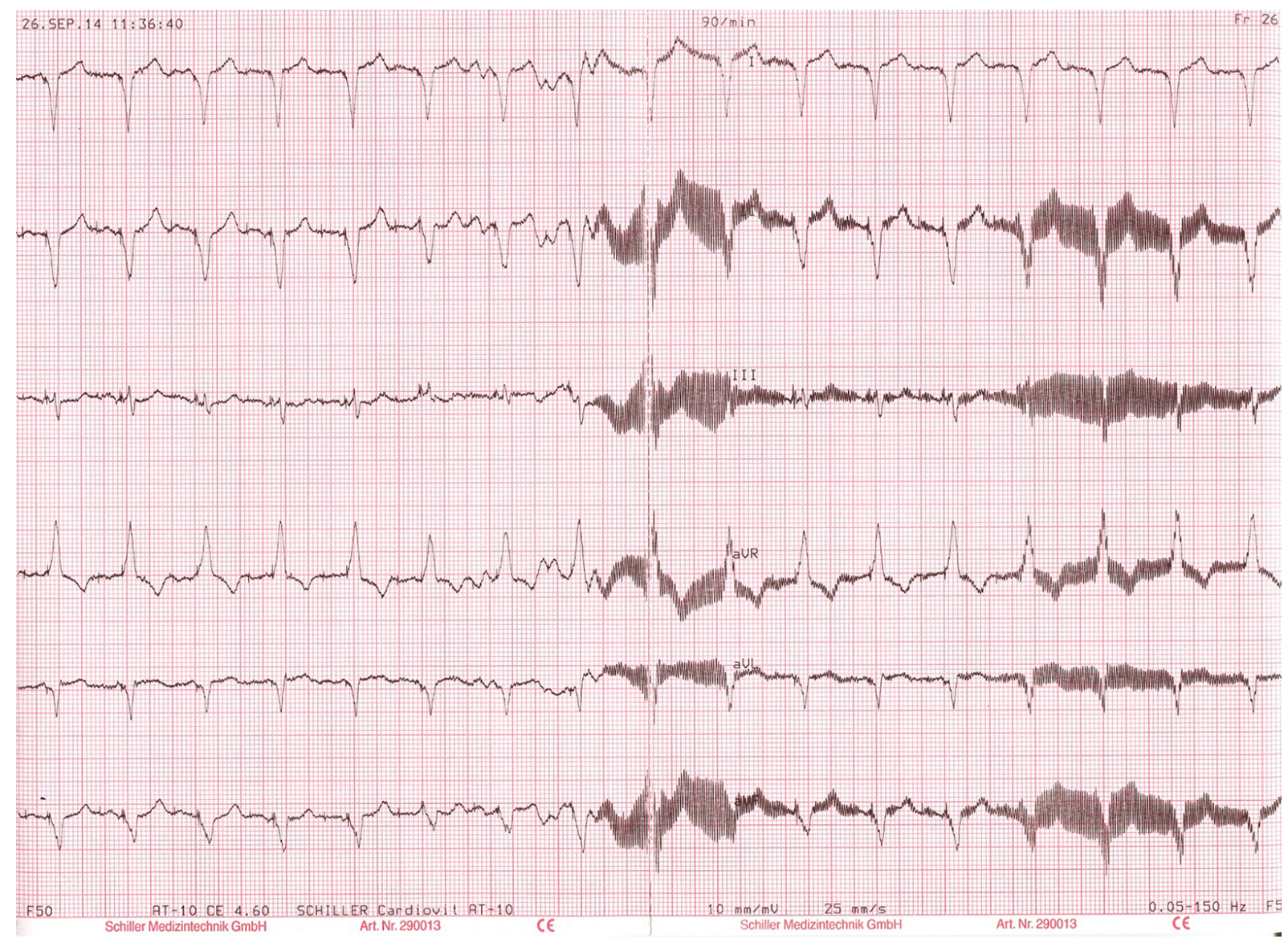

Fig. 2. High frequency, low amplitude EMI seen during testing.

hundred and eighty-three leads (75 atrial and 108 ventricular) comprising 42 lead families from 7 manufacturers were tested (Table 5). The mean sensitivity was $0.43 \pm 0.24 \mathrm{mV}$ for the atrial leads and 1.16 $\pm 1.08 \mathrm{mV}$ for the ventricular leads. The sensing mode was bipolar in $99 \%(74 / 75)$ of atrial and $95 \%$ $(103 / 108)$ of ventricular leads; the remaining leads were programmed to unipolar sensing.

\subsection{Magnetic field}

The magnetic fields measured in and around the cars while driving on the test-bench and charging are shown in Fig. 1. The International Commission on Non-Ionizing Radiation Protection (ICNIRP) recommended exposure to magnetic fields for the general population varies with the magnetic field frequency and so field strengths are presented as absolute values (inclusive of all frequencies) and as a percentage of recommended exposure normalized for frequency [36]. The largest magnetic field measured was along the cable during charging; $116.5 \mu \mathrm{T}$ in the Tesla Model 85S in high current (32A) charge mode. The strength of the magnetic field in the cabin of the cars measured 2.1-3.6 $\mu \mathrm{T}$; there was no difference in the cabin measurements taken on the test-bench versus on-road driving. We found variation in the magnetic field around the cars; the largest values were adjacent to either the front or rear doors (Fig. 2).

The magnetic field of the test-bench measured in stand-by and with full-load torque was $1 \mu \mathrm{T}$. 


\subsection{Functional device interference}

We observed no evidence of EMI when driving nor when plugging in and charging. There were no episodes of over- or under-sensing, no inappropriate pacing or inhibition of pacing and no spontaneous device re-programming occurred. Pacing thresholds, sensing and lead impedance remained unchanged on post-test examination.

\subsection{Electromagnetic interference with ECG-machine}

The only EMI detected was with the ECG-machine. An example of the high-frequency EMI signal is shown in Fig. 2. The underlying pacemaker rhythm was not influenced as demonstrated by the constant, paced R-R intervals (CL $667 \mathrm{~ms}$ ) and there was no functional effect on the CIED when interrogated.

\section{Conclusions}

To our knowledge, this is the first study to evaluate the effect of electromagnetic fields and potential EMI produced by fully electric cars on CIEDs. We found no effect on CIED functional or programming during driving or charging.

Though our group have previously published the primary safety outcome of this study here we report the full methodological details and importantly the complete details of devices tested. This demonstrates the wide selection of devices studied and thus the generalisability of our results. Furthermore, it facilitates industry, physicians and patients to assess whether a particular device has been evaluated.

We aimed to maximise observation of detectable EMI by reducing tachyarrhythmia detection to minimal settings and placing patients in several locations in and around the car during maximal engine output and during charging.

Fully electric cars were selected because the electromagnetic field of hybrid vehicles varies due to concurrent internal combustion engine use. Moreover maximal power is usually higher in pure electric than in hybrid vehicle. Our results are consistent with a smaller study that investigated EMI in a single hybrid vehicle [37]. Nevertheless, important differences in our study include the testing of multiple models; all fully electric. This enabled evaluation of more powerful electric motors and their associated electromagnetic fields than is possible in hybrid vehicles. Furthermore, use of a resistive roller-bench rather than a suspended car for test drives allows maximal engine power output to be achieved and thus generation of maximum electromagnetic fields; circumstances impossible with a suspended car.

The magnetic fields within the cabin during road driving matched that during roller-bench testing. It is thus reasonable to assume that our measurements are representative of real-life driving.

Electric cars are designed with electromagnetic shielding to prevent interference with other on-board computer systems. Therefore, it is reasonable to anticipate the shielding also provides protection from EMI to CIEDs inside the car. Indeed, the magnetic field measured inside the cabin $(2.1-3.6 \mu \mathrm{T})$ was substantially less than outside the cars (up to $103 \mu \mathrm{T}$ for the BMW).

The main source of the electromagnetic field generated by electric cars is the battery, though there is contribution from the power inverters, wiring, and power steering pumps [32,38]. Differences in location of the battery and of other source components are the likely explanation for the variation of the electromagnetic field around the cars. However, the magnetic field detected around the cars is unlikely to be clinically relevant because it is only produced by moving cars and pedestrians would be exposed for a very short time. 
More potentially clinically-relevant exposures occurred during charging; the observed values were consistent with previous studies [32]. A plausible explanation for the higher values is that the charging cable is less shielded. Despite this, no events were detected during charging while standing next to the cable. It should be noted that the recommended exposure limits were designed to prevent adverse health outcomes and pertain to biological systems and not electronic devices. The field strength along the charging cable increased as current increased. This is relevant because of plans to increase charging capability to deliver up to $400 \mathrm{~A}$ (versus $32 \mathrm{~A}$ maximum in our study) and thereby produce larger electromagnetic fields [39].

Stunder et al. demonstrated that PM with nominal sensitivity settings encountered EMI in a magnetic field starting from $300 \mu \mathrm{T}$; moreover, with sensitivity maximized, EMI was first detected in a $130 \mu \mathrm{T}$ magnetic field [40]. This raises concerns regarding planned high current chargers, but is reassuring for the low field strength measured in the cabin.

No restrictions were placed on types of lead or device, thus increasing generalizability of our results. We did not study effects at speeds over $120 \mathrm{~km} / \mathrm{h}$, but magnetic fields are strongest with maximal acceleration and are unrelated to speed. Our results are not definitive evidence of safety; however, if there is EMI between electric vehicles and CIED, it would be a rare event. Future research should investigate potential EMI produced by super-charging cables and how to shield these cables for patients with CIEDs.

Although our sample size was too small to detect rare events (between 1 in 1,000 and 1 in 10,000) [29], other information supports the conclusion that riding in electric cars is safe for patients with CIEDs. First, magnetic fields can also be generated in gasoline-powered cars if the steel-belted tires are magnetized [41]; average values of $\sim 20 \mu \mathrm{T}$ were reported in the back seat for 12 different models and as high as $97 \mu \mathrm{T}$ close to the tires [42]. Similar values have been reported in electric trains and trams [43]. These values are comparable to those we measured. Nonetheless, we are unaware of EMI cases associated with cars or trains.

In summary, electromagnetic fields produced by electric cars did not affect function or programming of CIEDs in our cohort. These results suggest current electric cars are safe for patients with CIEDs and no restrictions on travelling in them are required. Nevertheless, vigilance is required to monitor for rare events, especially associated with vehicle charging and proposed super-charger technology.

\section{Acknowledgments}

The study was supported by the Karl and Lore Klein Stiftung. The funder had no role in study design, data collection and analysis, or reporting. The grant was used to rent the cars and test-bench and cover personnel costs.

\section{References}

[1] Brignole M, Auricchio A, Baron-Esquivias G, Bordachar P, Boriani G, Breithardt OA, et al. 2013 ESC Guidelines on cardiac pacing and cardiac resynchronization therapy. Europace. 2013; 15(8): 1070-118.

[2] Priori SG, Blomström-Lundqvist C, Mazzanti A, Blom N, Borggrefe M, Camm J, et al. 2015 ESC Guidelines for the management of patients with ventricular arrhythmias and the prevention of sudden cardiac death. Eur Heart J. 2015; 36(41): 2793-867.

[3] Tracy CM, Epstein AE, Darbar D, DiMarco JP, Dunbar SB, Estes NAM, et al. 2012 ACCF/AHA/HRS focused update incorporated into the ACCF/AHA/HRS 2008 guidelines for device-based therapy of cardiac rhythm abnormalities. J Am Coll Cardiol. 2013 Jan; 61(3): e6-75. 
[4] Ponikowski P, Voors AA, Anker SD, Bueno H, Cleland JGF, Coats AJS, et al. 2016 ESC Guidelines for the diagnosis and treatment of acute and chronic heart failure. Eur Heart J. 2016 Jul 14; 37(27): 2129-200.

[5] Mond HG, Proclemer A. The 11th world survey of cardiac pacing and implantable cardioverter-defibrillators: calendar year 2009-a World Society of Arrhythmia's project. Pacing Clin Electrophysiol. 2011 Aug; 34(8): 1013-27.

[6] Greenspon AJ, Patel JD, Lau E, Ochoa JA, Frisch DR, Ho RT, et al. 16-Year trends in the infection burden for pacemakers and implantable cardioverter-defibrillators in the United States: 1993 to 2008. J Am Coll Cardiol. 2011; 58(10): 1001-6.

[7] Hatala R, Lunati M, Calvi V, Favale S, Goncalvesová E, Haim M, et al. Clinical implementation of cardiac resynchronization therapy-regional disparities across selected ESC member countries. Ann Noninvasive Electrocardiol. 2015 Jan; 20(1): 43-52.

[8] Leitgeb N, Cech R, Schröttner J, Lehofer P, Schmidpeter U, Rampetsreiter M. Magnetic emissions of electric appliances. Int J Hyg Environ Health. 2008 Mar; 211(1-2): 69-73.

[9] Gajšek P, Ravazzani P, Grellier J, Samaras T, Bakos J, Thuróczy G. Review of Studies Concerning Electromagnetic Field (EMF) Exposure Assessment in Europe: Low Frequency Fields $(50 \mathrm{~Hz}-100 \mathrm{kHz})$. Int J Environ Res Public Health. 2016 Sep 1; 13(9): 875

[10] Dawson TW, Caputa K, Stuchly MA, Shepard RB, Kavet R, Sastre A. Pacemaker interference by magnetic fields at power line frequencies. IEEE Trans Biomed Eng. 2002 Mar; 49(3): 254-62.

[11] Scholten A, Silny J. The interference threshold of unipolar cardiac pacemakers in extremely low frequency magnetic fields. J Med Eng Technol. 2001; 25(5): 185-94.

[12] Beinart R, Nazarian S. Effects of external electrical and magnetic fields on pacemakers and defibrillators: from engineering principles to clinical practice. Circulation. 2013 Dec 24; 128(25): 2799-809.

[13] Misiri J, Kusumoto F, Goldschlager N. Electromagnetic interference and implanted cardiac devices: the nonmedical environment (Part I). Clin Cardiol. 2012 May; 35(5): 276-80.

[14] Medtronic. Answers to Questions about Implantable Cardiac Devices, electromagnetic compatability guide [Internet]. 2016 [cited 2016 Sep 5]. Available from: http://www.medtronic.com/content/dam/medtronic-com-m/mdt/documents/ emc_guide.pdf.

[15] StJude. ICD and Pacemaker Interference: Dealing With EMI [Internet]. [cited 2017 Sep 5]. Available from: https://www. sjm.com/en/patients/arrhythmias/living-with-your-treatment/electromagnetic-interference?alert=DeepLinkSoftAlert\& clset=af584191-45c9-4201-8740-5409f4cf8bdd\%3Ab20716c1-c2a6-4e4c-844b-d0dd6899eb3a.

[16] Kolb C, Zrenner B, Schmitt C. Incidence of electromagnetic interference in implantable cardioverter defibrillators. Pacing Clin Electrophysiol. $2001 \mathrm{Apr}$; 24(4): 465-8.

[17] Trigano A, Blandeau O, Dale C, Wong MF, Wiart J. Reliability of electromagnetic filters of cardiac pacemakers tested by cellular telephone ringing. Hear Rhythm. 2005; 2(8): 837-41.

[18] Naegeli B, Osswald S, Deola M, Burkart F. Intermittent pacemaker dysfunction caused by digital mobile telephones. J Am Coll Cardiol. 1996 May; 27(6): 1471-7.

[19] Hofgärtner F, Müller T, Sigel H. Could C- and D-network mobile phones endanger patients with pacemakers? DMW Dtsch Medizinische Wochenschrift. 2008 Mar 25; 121(20): 646-52.

[20] von Olshausen G, Rondak I-C, Lennerz C, Semmler V, Grebmer C, Reents T, et al. Electromagnetic interference in implantable cardioverter defibrillators: present but rare. Clin Res Cardiol. 2016 Aug; 105(8): 657-65.

[21] Handelsblatt. Prognose zum weltweiten Umsatz mit Elektrofahrzeugen von 2010 bis 2030. Optional translation of article title: Forcast for global sales of electric cars from 2010 to 2030. [Internet]. [cited 2017 Aug 19]. Available from: https:// de.statista.com/statistik/daten/studie/173157/umfrage/prognose-zum-weltweiten-umsatz-mit-elektrofahrzeugen/\%0A.

[22] WirtschaftsWoche. Politisch gewünschte Anzahl der Elektroautos im Jahr 2020 nach Ländern. Optional translation of article title: Political targets for the number of electric cars in 2020 by country. [Internet]. [cited 2017 Aug 19]. Available from: https://de.statista.com/statistik/daten/studie/180290/umfrage/politisch-gewuenschte-anzahl-der-elektroautosim-jahr-2020/.

[23] A European Strategy for Low-Emission Mobility - Commission to the European parliament, the council, the European economic and social committee and the committee of the regions [Internet]. [cited 2017 Oct 16]. Available from: https:// ec.europa.eu/transport/sites/transport/files/themes/strategies/news/doc/2016-07-20-decarbonisation/com\%282016\%295 01_en.pdf.

[24] Volkswagen UK. Volkswagen eUP specifications [Internet]. [cited 2017 Oct 16]. Available from: www.volkswagen.co.uk /new/up-pa/which-model-compare/details/2800\#!\#tech-spec.

[25] Tesla Motors. Tesla Models S specifications [Internet]. [cited 2017 Oct 16]. Available from: www.tesla.com/en_GB/ models.

[26] AC Delco 336-2060 Starter, Autoparts Warehouse [Internet]. [cited 2017 Oct 17]. Available from: http://www.autoparts warehouse.com/sku/AC_Delco/Starter/AC3362060.html.

[27] Bimmertoday.de. Anzahl der Neuzulassungen von Elektroautos in Europa im Jahr 2014 nach Modellen. Optional translation of article title: Number of registrations of electric cars in Europe in 2014 by model [Internet]. [cited 2017 
Feb 5]. Available from: http://de.statista.com/statistik/daten/studie/431419/umfrage/anzahl-verkaufter-elektroautos-ineuropa\%0A.

[28] Lennerz C, O'Connor M, Horlbeck L, Michel J, Weigand S, Grebmer C, et al. Electric cars and electromagnetic interference with cardiac electronic implantable devices: a cross-sectional evaluation. Ann Intern Med. 2018; 169(5): 350-352. https://annals.org/aim/article-abstract/2679357/electric-cars-electromagnetic-interference-cardiac-implantable-electron ic-devices-cross-sectional.

[29] A Guideline on summary of product characteristics - Consumer goods, Pharmaceuticals - European commission for enterprise and industry [Internet]. [cited 2017 Oct 16]. Available from: https://ec.europa.eu/health//sites/health/files/files/ eudralex/vol-2/c/smpc_guideline_rev2_en.pdf.

[30] BMW. BMW i3 Specifications [Internet]. [cited 2017 Oct 16]. Available from: www.bmwusa.com/standard/content/ vehicles/2017/i3/bmwi3/features_and_specs/default.aspx.

[31] Nissan USA. Nissan leaf specifications [Internet]. [cited 2017 Oct 16]. Available from: www.nissanusa.com/electriccars/leaf/.

[32] Vassilev A, Ferber A, Wehrmann C, Pinaud O, Schilling M, Ruddle A. Magnetic field exposure assessment in electric vehicles. IEEE Trans Electromagn Compatability. 2015; 57(1): 35-43.

[33] Lennerz C, Pavaci H, Grebmer C, Semmler V, ier F, Haller B, et al. Electromagnetic interference in cardiac implantable electronic devices. J Am Coll Cardiol. 2017 Jan; 69(1): 108-10.

[34] Kolb C, Schmieder S, Lehmann G, Zrenner B, Karch MR, Plewan A, et al. Do airport metal detectors interfere with implantable pacemakers or cardioverter-defibrillators? J Am Coll Cardiol. 2003 Jun; 41(11): 2054-9.

[35] Jilek C, Tzeis S, Vrazic H, Semmler V, Andrikopoulos G, Reents T, et al. Safety of screening procedures with hand-held metal detectors among patients with implanted cardiac rhythm devices. Ann Intern Med. 2011 Nov 1; 155(9): 587.

[36] ICNIRP. ICNIRP Guidelines for limiting exposure to time-varying electric, magnetic and electromagnetic fields [Internet]. [cited 2017 Sep 5]. Available from: www.icnirp.org/cms/upload/publications/ICNIRPemfgdl.pdf

[37] Tondato F, Bazzell J, Schwartz L, Mc Donald BW, Fisher R, Anderson SS, et al. Safety and interaction of patients with implantable cardiac defibrillators driving a hybrid vehicle. Int J Cardiol. 2017 Jan; 227: 318-24.

[38] Concha P, Velez P, Lafoz M, Arribas J. Passenger exposure to magnetic fields due to the batteies of an electric vehicle. IEEE Trans Veh Technol. 2016; 65(6): 4564-71.

[39] Foley A, Winning I, O'Gallachoir B. State-of-the-Art in Electric Vehicle Chargng Infrastructure. In: Vehicle Power and Propulsion Conf IEEE. 2010. pp. 1-6.

[40] Stunder D, Seckler T, Joosten S, Zink MD, Driessen S, Kraus T, et al. In vivo study of electromagnetic interference with pacemakers caused by everyday electric and magnetic fields. Circulation. 2017 Feb 28; 135(9): 907-9.

[41] Milham S, Hatfield J, Tell R. Magnetic fields from steel-belted radial tires: implications for epidemiologic studies. Bioelectromagnetics. 1999; 20(7): 440-7.

[42] Stankowski S, Kessi A, Becheiraz O, Meier-Engel K, Meier M. Low frequency magnetic fields induced by car tire magnetization. Health Phys. 2006 Feb; 90(2): 148-53.

[43] Halgamuge MN, Abeyrathne CD, Mendis P. Measurement and analysis of electromagnetic fields from trams, trains and hybrid cars. Radiat Prot Dosimetry. 2010 Oct 1; 141(3): 255-68. 